\title{
DID THE LABOUR MARKET MATCHING EFFICIENCY CHANGE IN POLAND IN 2003-2008? ${ }^{1}$
}

The author addresses the problem of potential fluctuations in the matching process efficiency in Poland in the time span of 2003-2008. This period reflects a systematic upward movement along a Beveridge curve, so we can expect minor (if any) reallocation and efficiency changes. However, knowing that the trade process is time- and resource-consuming and that on average it depends on the number of agents in the labour market and other variables, the author expresses doubt if it is homogenous even along the UV curve.

The author uses aggregate time series and estimates various matching functions models handling econometrically for temporal aggregation bias in the data, and employs the concept of augmented matching function. At the disaggregated level the assumption of agents homogeneity is tested and the values of several mismatch indices in occupational and regional perspectives are computed. The aggregate matching function models estimates are in line with theoretical indications and prove no changes in the efficiency of the labour market matching process. It is hard, however, to confirm the assumption of agents homogeneity. In general, the analysed time span is characterized by an increase of labour market tightness indices, a decrease of unemployment rates and, in fact, minor mismatch changes (a slight increasing tendency with negligible value changes). This set indicates a lower aggregate disequilibrium.

Keywords: matching function, mismatch, data temporal aggregation

JEL Classifications: J63; J64

DOI: 10.15611 aoe.2017.2.04

\section{INTRODUCTION}

This article addresses the problem of potential fluctuations in the efficiency of the labour market matching process in Poland in 2003-2008. The author suggests that even along the $U V$ curve we can expect some changes in this efficiency. The studied period was characterized by a secular

\footnotetext{
* Department of Economics I, Warsaw School of Economics.

${ }^{1}$ I acknowledge with thanks financial support from the National Science Centre Poland, project no. UMO-2012/05/N/HS4/00194. I thank Fernando Núñez and Pablo Álvarez de Toledo from the University of Seville, and Carlos Usabiaga from the Pablo de Olavide University, Seville - for providing the algorithm which was used to estimate the matching function models while econometrically handling the temporal aggregation bias using the Coles, Petrongolo (2008) approach. I thank Elżbieta Antczak for computational assistance in generating Figures 2 and 3.
} 
decrease in the unemployment rate (from $20.1 \%$ to $7.2 \%$ ), an increase in employment ratio (from $55.7 \%$ to $64.9 \%$ ) and negligible changes in activity rate for the population of production age. These changes were induced, among others, by economic growth and considerable labour force emigration (caused by the European Union accession in 2004). In the matching perspective, the aggregate data show a systematic upward movement along a Beveridge curve. Thus, the positive aggregate activity changes occurred with minor (if any) reallocation movements (Blanchard and Diamond 1989). On the other hand, other characteristics indicate that the labour market matching process might have changed. The labour market situation improved, the tightness index increased and this could have induced a rise in the on-the-job and out-of-labour force flows. Higher chances of finding a new job could have encouraged workers to participate in a search process. It could have also, by increased churning in the market, affected not only the number of matches but also the quality of them. The aim is to identify the factors that affected the aggregate labour market matching function along the Beveridge curve. The potential findings can be used to formulate policy recommendations directed at increasing the job creation process.

The author finds that the matching took place randomly during the analysed time span, although the job seekers matched with the vacancy stock and vacancy inflow. Augmented matching function estimates implied no changes in the efficiency of the labour market matching process. It is hard to claim that the agents' pool was homogenous nor remained unchanged. Overall, the analysed time span was characterized by an increase in the labour market tightness indices, a decrease in the unemployment rates and, in fact, minor changes in mismatch. This set of changes indicates a lower aggregate disequilibrium and the need to improve information to further support job creation.

The rest of a paper is organized as follows. First (Section 2), a short literature survey concerning process efficiency in a macroeconomic perspective is made. Section 3 examines aggregate time series and estimates various matching function models handling econometrically for temporal aggregation bias in the data using the concept of augmented matching function to verify various time trend forms. Section 4 tests agents homogeneity assumption, and examines whether the structures of job seekers and vacancy pools changed considerably. Section 5 extends the analysis by looking at a more disaggregated level and computes several mismatch indices (e.g. regional or occupational). In Section 6 the findings are discussed and in Section 7 major concluding remarks are compiled. 


\section{TRADE PROCESS EFFICIENCY}

In the aggregate perspective, the matching process efficiency can be analysed by employing the concept of an augmented matching function (Lehmann 1995; Puhani 1999). Quantitatively it can be analysed through $A$ (an index reflecting efficiency of the labour market functioning) of the following functional form:

$$
M=A U^{\eta_{U}} V^{\eta_{V}}
$$

where:

$M$ - number of matches,

$U$ - number of job seekers,

$V$ - number of vacancies,

$\eta_{U}, \eta_{V}$ - matching function elasticities with respect to unemployment and vacancies respectively.

$A$ can be specified using various forms of the time trend. Direct variables can reflect, for example, mismatch, job search activity, demographic features, unemployment benefits and labour market policies (Lehmann 1995; Lindeboom et al. 1994; Petrongolo and Pissarides 2001). Alternatively, Puhani (1999) extends the matching function by using search effective unemployment stock $(\psi U)$. The function takes the form: $M=A(\psi U)^{\eta_{U}} V^{\eta_{V}}$ and $\psi$ is a search index which can be affected by various factors. The augmented matching function was widely used in analyses concerning the Polish labour market. Gałecka (2008) and Roszkowska (2009) compiled the results of numerous papers. Most often the authors did not directly name the matching mechanism, but the results implied that matching took place primarily between the unemployment stock and vacancy inflow. Previous research verified the impact of various determinants of the process efficiency and used data at country or regional level. Quarterly and annual data were employed in different time spans usually reflecting various movements of unemployment and vacancy rates in $u-v$ space.

In the matching function, mean transition rates depend on the mean number of market participants (and search and recruitment methods). Externalities arise as agents do not account for the influence of their actions on transition probabilities of other agents (Pissarides 1988). Positive externality (thick market effect) takes place when actions performed by job seekers ease finding a worker by companies, and analogously when recruitment methods performed by companies ease finding a job by work 
seekers. Negative externality (congestion effect) occurs when intensified search actions performed by agents on one side of the market reduce transition probabilities for other agents on the same side. Turnover externalities make all traders better off with higher entry rates of new market participants (Coles 1999).

Interestingly, externalities are connected to returns to scale effects. For a Cobb-Douglas matching function, $\eta_{U}\left(\eta_{V}\right)$ measures positive externality generated by the unemployed (vacancies), $\eta_{U}-1\left(\eta_{V}-1\right)$ measures the crowding-out effect exerted by the unemployed individuals (vacancies) on the unemployed individuals (vacancies) (Petrongolo and Pissarides 2001). The sum of the parameters determines the scale effects. Petrongolo and Pissarides (2006) found that constant returns to scale on an aggregate level can coexist with scale effects in the quality of job matches or in the arrival rate of job offers. The scale effect can be mostly connected to the distribution of wage offers, but better quality job matches most probably arise in large markets (Petrongolo and Pissarides 2006). Increasing returns to scale may generate the existence of multiple equilibria characterized by the diversified amount of effort put into the search process (Diamond 1982).

\section{MATCHING FUNCTION MODELS' ESTIMATES}

In the first part of the quantitative analysis, the author estimated matching function models at macroeconomic level. There are two main frameworks which differently explain the matching process which can be either random or non-random. In the first option, job seekers are assigned to job posts and a match occurs when both parties meet. Vacancies and unemployment coexist due to coordination failure in agents actions even if demand equals supply (Hall 1979; Blanchard and Diamond 1994).

At the other extreme, if we assume perfect information and agents heterogeneity, matching can be described by a stock-flow model. Trade takes place between a stock on one side with an inflow on the other side of the market. In the current period all trade options are exploited, so those left on the market are the agents for whom there is no proper partner and not because they have not met such yet (Coles and Smith 1998; Gregg and Petrongolo 2005; Taylor 1995).

In the job queuing framework, matching takes place randomly, but due to large discrepancies between demand and supply the unemployed individuals wait for new job opportunities (inflow of vacancies) (Shapiro and Stiglitz 
1984). Table 1 is a compilation of formulas for matching rates for unemployment stock $(\lambda)$ and unemployment inflow $(p)$ according to particular models assumptions. The augmented matching function concept can be applied to either framework.

Table 1

Matching rates formulas for unemployment stock and inflow in particular models

\begin{tabular}{l|c|c}
\hline \multicolumn{1}{c|}{ Model / matching rate } & $\begin{array}{c}\text { For unemployment } \\
\text { stock }\end{array}$ & $\begin{array}{c}\text { For unemployment } \\
\text { inflow }\end{array}$ \\
\hline stock-based model (random matching) & $\lambda=\lambda(U, V)$ & - \\
\hline job queuing framework (random matching) & $\lambda=\lambda(U, v)$ & - \\
\hline stock-flow model (non-random matching) & $\lambda=\lambda(U, v)$ & $p=p(u, V)$ \\
\hline
\end{tabular}

$\lambda$ - unemployment stock matching rate, $p$ - unemployment inflow matching rate, $U$ unemployment stock, $V$ - vacancy stock, $v$ - vacancy inflow

Source: own preparation.

The author estimated parameters using solutions proposed by Gregg and Petrongolo (2005) and Coles and Petrongolo (2008). Both frameworks tackle the problem of temporal aggregation bias in the data. The problem occurs when continuous time economic processes are described using data presented in a discrete manner. Time aggregated models treat an inflow as a determinant of a stock value so they more properly reflect particular agents pools.

The time span of 2003-2008 was examined using monthly registered unemployment data. The dependent variable was the outflow from unemployment to employment, although the hiring could not be equated with public employment offices intermediation. Job seekers were approached by registered unemployment, the vacancies were those posted in employment offices. The time span reflected an upward movement along the Beveridge curve, so the market should not have experienced major changes in reallocation or changes in the process efficiency. The sub-period 20022004 reflects the jobless recovery caused mainly by labour productivity growth (Drozdowicz-Bieć 2012). In 2008 the UV curve reversed.

Outflow from unemployment to employment constituted on average $0.44 \pm 0.04$ of the total outflow and ranged between $(0.36 ; 0.54)$. Only the time series referring to vacancies had higher means than medians. Most of the series were left skewed, vacancy stock was right skewed, unemployment 
and vacancy inflows were almost symmetric. The coefficient of variation was the highest one for vacancy variables (especially vacancy stock) and the lowest for unemployment inflow and outflow variables (less than 10\%). Vacancies were more volatile and should have enjoyed a lower expected duration. Monthly inflow/stock ratio ranged for vacancies between (1.19; $4.24)$ with mean 2.35 , whereas for unemployment - between $(0.06 ; 0.15)$ with mean 0.09 . Time series displayed a high degree of persistence, monthly correlation coefficients were higher in the case of stock variables. The ADF and Phillips-Perron tests indicated that at the 5\% significance level for either levels or first differences the null hypothesis of unit root existence in particular time series should have been rejected.

Previous analyses (Gałecka-Burdziak 2017) did not enable to discredit any of the recalled models, so the author estimated all the frameworks. The estimation method was non-linear least squares including first order serial correlation in a disturbance term to deal with autocorrelation. Full stock-flow model estimates were statistically insignificant so they were omitted. The results were compiled in Table 2 presenting structural parameters' estimates and basic statistics, for example, sample averages of model predictions for hazard rate or matching function elasticities. Point results are not directly comparable as Gregg and Petrongolo's framework enables counting elasticities with respect to stocks and flows, while Coles and Petrongolo's solution yields results with respect to 'at risk' measures. Other statistics, however, yielded coherent results.

The unemployed matched the vacancy stock. Gregg and Petrongolo's framework yielded higher elasticities with respect to supply variables (so higher positive externalities were exerted by the unemployed on vacancies), while the other solution emphasized the impact of demand (larger positive impact generated by vacancies on job seekers). Vacancy inflow elasticity was at a comparable level in both job queuing estimates; and did not differ statistically significantly. Vacancy stock (pool) experienced non-negligible elasticity, which was higher in Coles and Petrongolo's model estimates. The pool, however, included vacancy inflow.

Figure 1 presents matching function elasticities with respect to unemployment stock and vacancy counterpart according to the model specification - vacancy stock in the case of column I of Table 2, vacancy inflow in the case of column II of Table 2. Unemployment inflow elasticities were almost identical in both models. Visual inspection reveals the interdependence of the respective matching pairs. ADF tests proved that all series were stationary so the inference could be verified with correlation 
Table 2

Estimates of time aggregated matching models, 2003-2008

\begin{tabular}{|c|c|c|c|c|}
\hline \multirow[t]{2}{*}{$\begin{array}{c}\text { Independent } \\
\text { variable/ } \\
\text { statistics }\end{array}$} & \multicolumn{4}{|c|}{$\begin{array}{l}\text { Parameters estimates } \\
\text { (t-student statistics) }\end{array}$} \\
\hline & $\begin{array}{c}(\mathrm{I}) \\
\text { stock-based } \\
(\mathrm{G}, \mathrm{P})\end{array}$ & $\begin{array}{c}\text { (II) } \\
\text { job queuing } \\
(\mathrm{G}, \mathrm{P})\end{array}$ & $\begin{array}{c}\text { (Ib) } \\
\text { stock-based } \\
(\mathrm{C}, \mathrm{P})\end{array}$ & $\begin{array}{l}\text { (IIb) } \\
\text { job queuing } \\
(\mathrm{C}, \mathrm{P})\end{array}$ \\
\hline$\alpha_{1}\left(U_{t} \rightarrow V_{t}\right)$ & $\begin{array}{c}0.227 \\
(23.21)\end{array}$ & - & - & - \\
\hline$\alpha_{2}\left(U_{t} \rightarrow v_{t}\right)$ & - & $\begin{array}{c}0.416 \\
(26.32) \\
\end{array}$ & - & - \\
\hline$\beta_{1}\left(\bar{U}_{t}\right)$ & - & - & $\begin{array}{l}-0.261 \\
(-4.07)\end{array}$ & $\begin{array}{l}-0.410 \\
(-10.04)\end{array}$ \\
\hline$\beta_{2}\left(\bar{V}_{t}\right)$ & - & - & $\begin{array}{l}0.434 \\
(7.83) \\
\end{array}$ & - \\
\hline$\beta_{3}\left(v_{t}\right)$ & - & - & - & $\begin{array}{l}0.443 \\
(9.55) \\
\end{array}$ \\
\hline$\lambda$ & $0.0433 \pm 0.008$ & $\begin{array}{l}0.0434 \\
\pm 0.008\end{array}$ & $0.0434 \pm 0.008$ & $\begin{array}{l}0.0433 \\
\pm 0.008\end{array}$ \\
\hline $\begin{array}{c}R^{2} \\
\left(\operatorname{adj} . R^{2}\right)\end{array}$ & $\begin{array}{l}0.835 \\
0.830\end{array}$ & $\begin{array}{l}0.882 \\
0.878\end{array}$ & $\begin{array}{l}0.859 \\
0.853\end{array}$ & $\begin{array}{l}0.882 \\
0.876\end{array}$ \\
\hline $\begin{array}{l}\text { ADF test for } \\
\text { residuals } \\
\text { (p-value) }\end{array}$ & $\begin{array}{l}-8.94 \\
(0.00)\end{array}$ & $\begin{array}{l}-8.48 \\
(0.00)\end{array}$ & $\begin{array}{l}-9.27 \\
(0.00)\end{array}$ & $\begin{array}{l}-8.36 \\
(0.00)\end{array}$ \\
\hline $\begin{array}{c}\text { Mean } \\
\text { unemployme } \\
\text { nt duration } \\
\text { (in months): }\end{array}$ & 23 & 23 & 23 & 23 \\
\hline \multicolumn{5}{|l|}{ Elasticities: } \\
\hline$\frac{\partial M}{\partial U} \frac{U}{M}$ & $0.737 \pm 0.037$ & $0.551 \pm 0.024$ & - & - \\
\hline$\frac{\partial M}{\partial u} \frac{u}{M}$ & $0.044 \pm 0.011$ & $0.044 \pm 0.011$ & - & - \\
\hline$\frac{\partial M}{\partial V} \frac{V}{M}$ & $0.224 \pm 0.011$ & - & - & - \\
\hline$\frac{\partial M}{\partial v} \frac{v}{M}$ & - & $0.409 \pm 0.016$ & - & - \\
\hline
\end{tabular}

$u$ - unemployment inflow, $(\mathrm{G}, \mathrm{P})$ - Gregg, Petrongolo framework, $(\mathrm{C}, \mathrm{P})$ - Coles, Petrongolo framework, data seasonally adjusted, dependent variable - outflow from unemployment to employment

Source: own calculation. 
coefficients analysis. For model I the correlation coefficient between the unemployment stock elasticity and vacancy stock elasticity was 0.98 , and for model II the correlation coefficient between the unemployment stock elasticity and vacancy inflow elasticity was 0.95 .

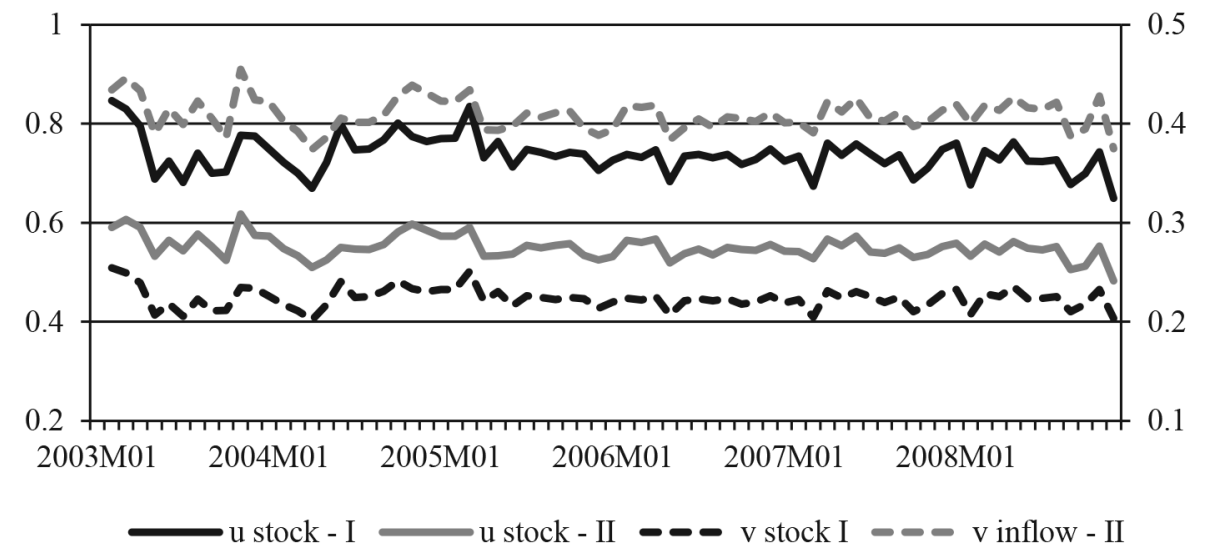

Figure 1. Matching function elasticities with respect to unemployment stock (left axis), and vacancy stock and inflow (right axis) (models I and II), 2003-2008

Source: own calculation.

So far, the author has assumed no changes in the efficiency of the matching process. If the opposite was true, the other variables should have statistically significantly explained parallel movements of the matching function. First, the author addressed this assumption and included the time trend (linear, quadratic or cubic) in the specifications of the augmented matching function to reflect any (non)linear changes in the efficiency of the matching process. In none of the specifications, time trend parameters were statistically significant. This finding implies no changes in the process efficiency.

\section{HOMOGENOUS POOLS?}

A simple random model assumes perfect agents homogeneity. If a vacancy has more than one application, a worker is assigned randomly. This implies that the exit rate from a pool is independent of the search duration process. In a stock-flow model the probability of leaving the market is a decreasing function of the search duration, and agents are said to be heterogeneous. 
In this section the author addressed potential changes in the process efficiency by looking at the structures of demand and supply (occupational and regional dimensions are analysed in Section 5). Changing structures influence matching probabilities of the agents, as the employability of particular job seekers varies and job posts are perceived as bad or good. The author checked whether search methods changed during the analysed time span, although the analysis referred primarily to the public employment intermediation.

Registered unemployment data showed that churning increased. At the beginning of 2003 unemployment inflow constituted around 0.06 of the stock, while at the end of $2008-0.15$. The stock structure was not homogenous. The share of the unemployed individuals living in rural areas increased by 4 percentage points to $45 \%$. The share of job seekers unemployed longer than 12 months oscillated around $50 \%$ up to the end of 2007 , but declined to almost $33 \%$ at the end of 2008. The share of job seekers (from the stock) eligible for unemployment benefits was relatively constant. In 2003 around $30 \%$ of the newcomers could get the benefit, but in 2008 less than $20 \%$ of the inflow were eligible for the unemployment benefits. Those who registered at employment offices did not fulfil the legal requirements to obtain unemployment benefit, but some of them may have registered for the first time having seen their employment chances improved due to the increased number of job offers.

LFS data showed that more job seekers used particular search methods. Some of the series experienced a jump increase in 2004 (the end of jobless growth) and a slight decrease in 2008 which corresponded to a decrease in the size of the vacancy rate. Among the most popular methods one could include: (i) asking friends, relatives, trade unions (around 75\%), (ii) studying advertisements (around 70\%), (iii) contacting public employment office (around 70\%) and (iv) applying directly to employers (around 60\%). Only 1 out of 15 job seekers contacted private employment agency.

Large worker flows imply that inflows to employment did not originate from unemployment only. Changing conditions could encourage or discourage particular job seekers (recruiting from other than unemployment pools) to engage actively in the search process. The literature unambiguously states that job-to-job moves are procyclical. The same inference appears to be true with respect to flows from inactivity to employment (Antolín 1999; Petrongolo and Pissarides 2001). If various fractions of job seekers compete for the same jobs, there arises a congestion effect and the unemployed have lower chances of finding employment. Registered unemployment data 
showed that the unemployed constituted the vast majority of the total registered job seekers. LFS data provided the percentage of responders who indicated that they had looked for another job during the current work contract. This share was around $7-8 \%$ between $2003-2005$ but it declined to $3 \%$ in 2008. If we had added the absolute value of on-the-job seekers to the unemployed individuals they would have constituted substantial portion of the total job seekers pool. The same conclusion applies to out-of-work labour force search. Gałecka-Burdziak (2013) found that in the time span 2003-2007, 50\% of employment inflow originated from unemployment, while the rest, in equal shares, from inactivity and employment (close to one third in 2008). It might be questionable to assume that the unemployed individuals competed with other job seekers for job posts registered at public employment offices, however it is more straightforward to consider that all three groups competed for job posts offered by companies and not registered at public employment offices.

Entrepreneurs are obliged to announce job offers at public employment offices (The Act on the promotion of employment and labour market institutions of 2004). This regulation is not, however, actually respected. In 2012 approximately only $16.5 \%$ of companies published job offers at public employment offices (Badanie Ankietowe Rynku Pracy 2012). The positive difference between the outflow from unemployment to employment and the sum of the inflow of new vacancies during a month and the beginning-ofmonth vacancy stock indicates lower the bound of the size of the underestimation of the number of available job offers. Such bias confirms also that other than public employment services intermediation methods of job search and recruitment are important in Poland. Aggregate registered data showed that the vacancy inflow and stock were rising between 2003 and 2007. The inflow/stock ratio decreased from more than 4 in 2003 to 1.5 in 2008. The stock rose more than proportionally what resulted in an increased share of the offers not filled for more than a month (from $15 \%$ in 2003 to even $40 \%$ in 2008). Another aggregate effect was the decrease in the average number of the unemployed individuals per one job offer - from almost 70 at the beginning of 2003 to 13 at the beginning of 2008 .

Further knowledge concerning the general outlook of job opportunities can be drawn from analysing newspaper job offers - BOP (Job Offers Barometer, Drozdowicz-Bieć 2004). The index up to 2008 was based on newspaper job offers, and since 2008 it has been primarily based on job offers published in the Internet. Pater (2010) described the index and compared it to the demand for labour statistics presented by the Central 
Statistical Office. Pater (2010) concluded that both series behaved comparatively, and new vacancies and vacancy stock were generally rising between 2005 and 2008.

\section{MISMATCH}

Padoa-Schioppa (1991) lists four main approaches which define the concept of a mismatch. The first framework refers to short-term sectoral shocks, the others are associated with changes of a more permanent character: (i) the disequilibrium model, where each micro market employment level is determined by its short side, (ii) frictional unemployment (the mismatch is perceived as the difference between actual unemployment rate and its optimal level - the one that maximises hiring for equalised labour market tightness indices), (iii) variance of relative unemployment rates - the mismatch is perceived as the distance between the actual unemployment rate and its minimum value (the emphasis is put on price stability). The second framework gives the two most popular mismatch measures (Abraham 1991):

$M_{1}$ - the number of unemployed workers who need to be moved from one sector to another in order to achieve structural balance (Jackman and Roper 1987):

$$
M_{1}=\frac{1}{2} \sum\left|\hat{u}_{i}-\hat{v}_{i}\right|
$$

where:

$\hat{u}_{i}$ - share of unemployment in $i$ relative to aggregate unemployment,

$\hat{v}_{i}$ - share of vacancies in $i$ relative to aggregate vacancies.

$M_{2}$ - measures the contribution of structural imbalances to overall unemployment (Jackman and Roper 1987):

$$
M_{2}=1-\sum\left(\hat{u}_{i} \hat{v}_{i}\right)^{\frac{1}{2}}
$$

whereas the third mismatch indicator equals (Abraham 1991):

$$
M_{3}=\frac{1}{2} \operatorname{var}\left(\frac{u_{i}}{u}\right)
$$

$u_{i}$ - unemployment rate in $i$,

$u$-unemployment rate. 
Padoa-Schioppa (1991) also presents another approach of mismatch measurement (compare Table 3) - based on changes in $\frac{V}{U}$, unemployment rate and dispersion index. The index equals:

$$
M_{4}=\frac{1}{2} \sqrt{\frac{\sum\left(\frac{v_{i}}{u_{i}}\right)^{2} \eta_{i}}{\left(\sum \frac{v_{i}}{u_{i}} \eta_{i}\right)^{2}}}-1=\frac{1}{2} \sqrt{\sum\left(\frac{\hat{v}_{i}}{\hat{u}_{i}}\right)^{2} \eta_{i}}-1
$$

where:

$\eta_{i}$ - should be equal to the share of unemployment in $i$ relative to aggregate unemployment, $\hat{u}_{i}$,

$v_{i}$ - vacancy rate in $i$.

Table 3

Criteria identifying when mounting mismatch is uniquely responsible for the unemployment rate increase

\begin{tabular}{l|c|c|c}
\hline $\begin{array}{c}\text { Ceteris paribus } \\
\text { causes of change: }\end{array}$ & \multicolumn{2}{|c|}{$\begin{array}{c}\text { Outward shift } \\
\text { of a Beveridge curve: }\end{array}$} & $\begin{array}{c}\text { Upward shift of a straight } \\
\text { line of disequilibrium } \\
\text { unemployment: }\end{array}$ \\
\hline \multicolumn{1}{c|}{ Indices } & $\begin{array}{c}\text { Higher } \\
\text { mismatch }\end{array}$ & $\begin{array}{c}\text { Higher } \\
\text { frictions }\end{array}$ & $\begin{array}{c}\text { Lower aggregate } \\
\text { disequilibrium }\end{array}$ \\
\hline$(v / u)$ & + & + & + \\
\hline$M_{4}$ & + & $/$ & $/$ \\
\hline$u$ & + & + & - \\
\hline
\end{tabular}

Note: $(+)$ denotes a growth, $(-)$ a decrease, (/) shows a constant index, $M_{4}$ denotes the dispersion index.

Source: Padoa-Schioppa 1991, p. 19

Aggregate data for the time span 2003-2008 showed no parallel shifts of the Beveridge curve. $\frac{V}{U}$ ratio increased while unemployment decreased. The author computed the mismatch indices in regional and occupational dimensions and wanted to verify the hypothesis of potentially lower aggregate disequilibrium implied by theoretical considerations. First, the author tackled the problem at regional level. Figures 2 and 3 present data on regional unemployment and vacancy rates comparing to the country means. 


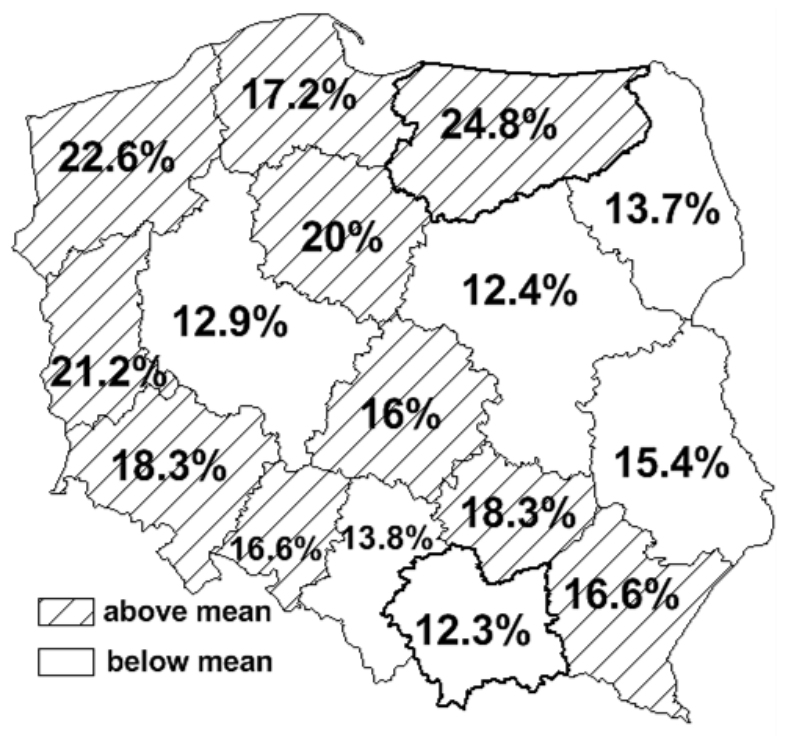

Figure 2. Regional unemployment rates (compared to country mean 15.8\%), 2003-2008 Source: own calculation

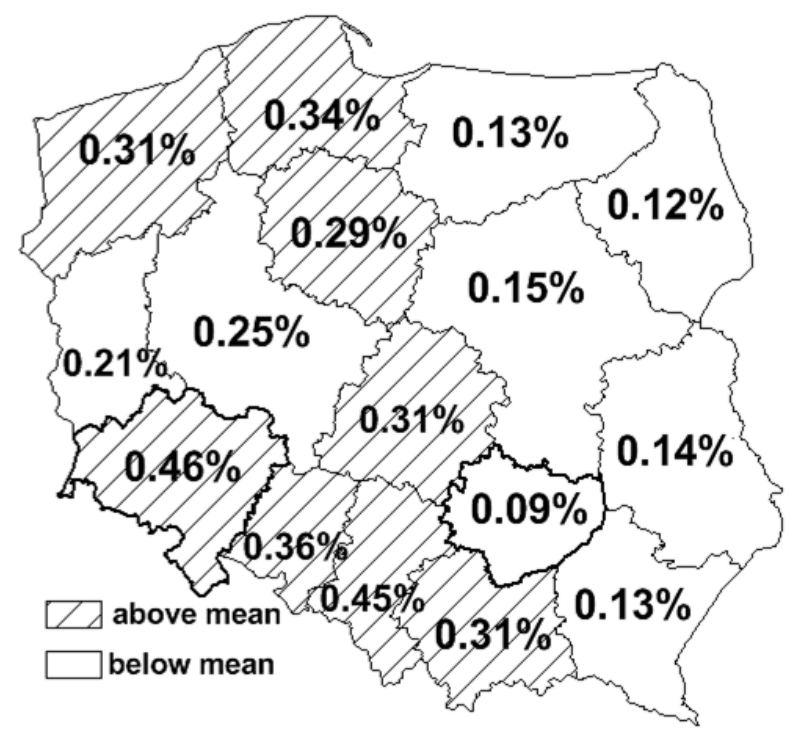

Figure 3. Regional vacancy rates (compared to country mean $0.27 \%$ ), 2003-2008 Source: own calculation. 
Contoured voivodeships are the ones with the highest and lowest mean values. We might distinguish regions with (i) both indicators above means, e.g. zachodnio-pomorskie, (ii) both indicators below means, e.g. mazowieckie, (iii) those with higher unemployment rates and lower vacancy rates, e.g. warmińsko-mazurskie and (iv) those with lower unemployment rates and higher vacancy rates, e.g. małopolskie. Lubuskie voivodeship experienced the largest difference between the maximum and minimum unemployment rates (14.3 percentage point), while podkarpackie the smallest one (6.2 percentage point). Opolskie had the largest difference between maximum and minimum vacancy rates ( 0.77 percentage point), while podlaskie, the smallest one ( 0.11 percentage point).

Interdependence of unemployment and vacancy rates induced an upward movement along a downward sloping UV curves for all voivodeships. For some of them the Beveridge curve reversed in 2007. Particular curves location in the $u-v$ space differed; around nine of them were situated further from the coordinate origin than the country one.

The author computed all four mismatch indices in regional dimension using annual registered unemployment data to avoid seasonality. $M_{1}, M_{2}, M_{3}$ (computed separately for unemployment and vacancies) are presented on the left axis, $M_{4}$ is presented on the right axis in Figure 4. All the indices yielded consistent conclusions. There was a general increase in the dispersion with minor intra period fluctuations. $M_{3}$ values were consequently increasing, though vacancies dispersion rose more than the unemployment one. $M_{1}$ and $M_{4}$ showed a decrease in mismatch between 2003 and 2005.

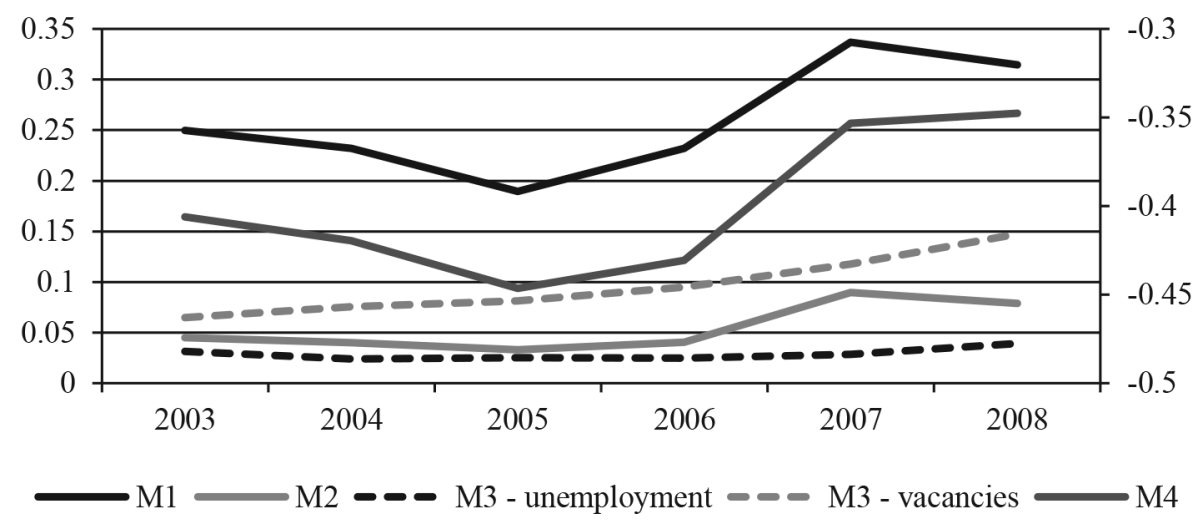

Figure 4. Regional mismatch indices, 2003-2008 ( $M_{4}$ - right axis)

Source: own calculation. 
Separate considerations concern occupational mismatch. Due to data availability the analysis referred to the 2004-2008 period. We can distinguish ten main occupational groups: (i) managers, (ii) professionals, (iii) technicians and associate professionals, (iv) clerical support workers, (v) service and sales workers, (vi) skilled agricultural, forestry and fishery workers, (vii) craft and related trades workers, (viii) plant and machine operators, and assemblers, (ix) elementary occupations, (x) armed forces occupations, and (xi) those with no occupation. The author combined some groups to present particular markets size (table 4) and competition among job seekers for vacancies.

Table 4

Occupational groups' shares in unemployment and vacancies

\begin{tabular}{l|c|c|c|c|c|c}
\hline & I & II & III & IV & V & VI \\
\hline $\begin{array}{l}\text { Unemployment } \\
\text { share }\end{array}$ & $0.067 \pm 0.01$ & $0.32 \pm 0.01$ & $0.029 \pm 0.00$ & $0.412 \pm 0.03$ & $0.001 \pm 0.00$ & $0.172 \pm 0.02$ \\
\hline Vacancies share & $0.073 \pm 0.01$ & $0.363 \pm 0.04$ & $0.003 \pm 0.00$ & $0.543 \pm 0.04$ & $0.000 \pm 0.00$ & $0.017 \pm 0.01$ \\
\hline $\begin{array}{l}\text { No. of job seekers } \\
\text { per vacancy }\end{array}$ & $6.5 \pm 1.1$ & $4.1 \pm 1.3$ & $16.4 \pm 3.9$ & $3.7 \pm 1.5$ & $14.7 \pm 11.8^{\mathrm{a}}$ & $93.9 \pm 34.8$ \\
$\frac{U+u}{V+v}$ & & & & & \\
\hline
\end{tabular}

Note: I - (i) and (ii); II - (iii), (iv) and (v); III - (vi); IV - (vii), (viii) and (ix); V - (x); VI (xi); ${ }^{\mathrm{a}}$ - without 2006 , which is an outlier.

Source: own calculation.

I

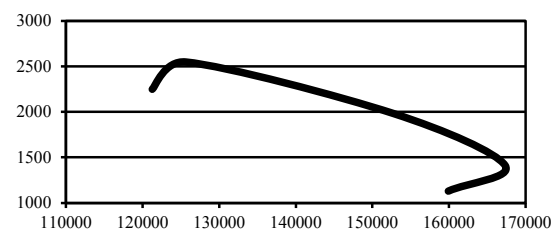

IV

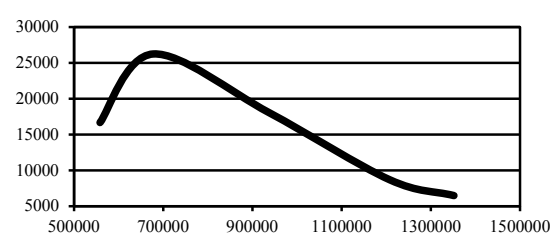

II

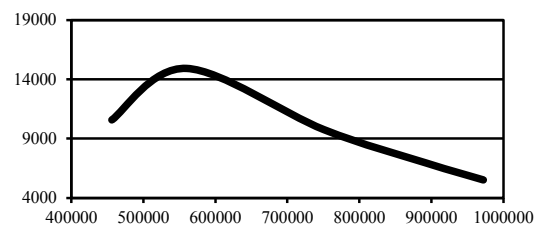

VI

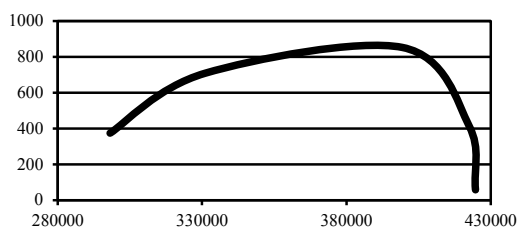

Figure 5. Occupational UV curves, curves (in absolute values, unemployment on horizontal axis, vacancies on vertical axis), 2004-2008

Source: Ministry of Labour and Social Policy, http://www.mpips.gov.pl, own calculation. 
Figure 5 presents the UV curves for four groups with the main shares in unemployment and vacancies - I, II, IV and VI. Interestingly, for groups I, II and IV the share of vacancies was higher than that of unemployment. Comparative analysis of the location of particular curves in space was limited due to the different size of micro markets and the lack of data concerning the rates. In all the cases the curves started to reverse at the end of the analysed time span.

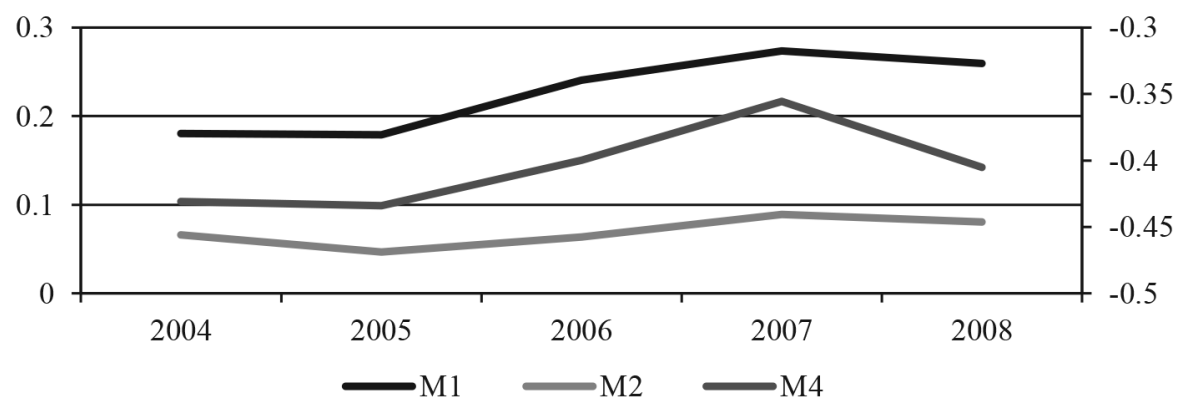

Figure 6. Occupational mismatch indices, 2004-2008 ( $M_{4}-$ right axis)

Source: own calculation.

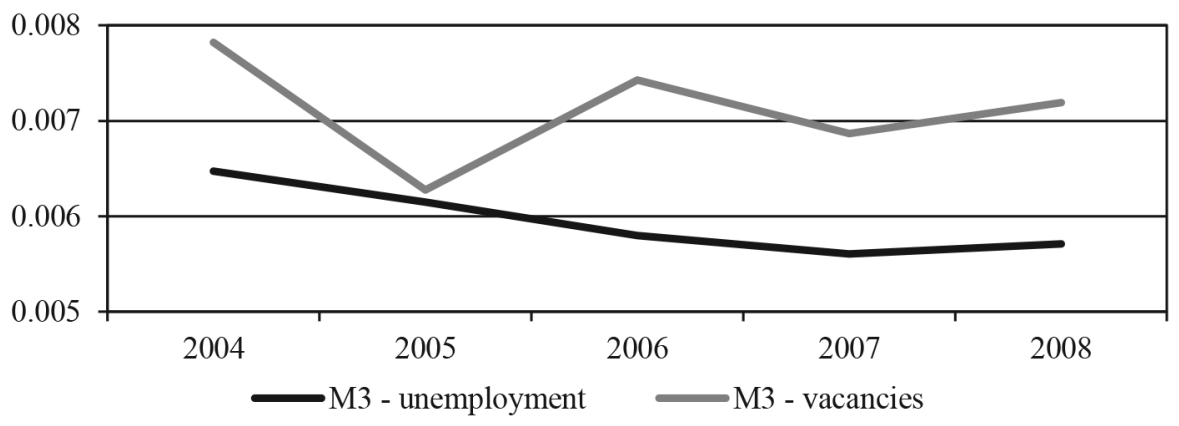

Figure 7. $M_{3}$ occupational mismatch indices, 2004-2008

Note: Indices are based on absolute values and not on rates.

Source: own calculation.

Figures 6 and 7 present occupational mismatch indices. Similar to the regional ones, $M_{4}$ is situated on the right axis, while the others on the left one. The general conclusions are consistent with previous ones. Mismatch was generally rising, although $M_{4}$ showed some decrease in 2008, $M_{3}$ for unemployment - 2004-2007 and for vacancies - in 2005 and 2007. 


\section{DISCUSSION}

The matching function estimates confirmed that job seekers matched with vacancy stock and vacancy inflow, but the matching was taking place randomly. The unemployment stock (pool) matched with the vacancy stock (pool). It seems though that the vacancy inflow mattered more. The exit rate from unemployment depended on an inflow-based labour market tightness index which confirms the importance of a vacancy inflow. Moreover, similar values of the parameters $\hat{\beta}_{2}$ and $\hat{\beta}_{3}$ imply that the "marginal effect" of a vacancy stock in the matching process was very small (once the vacancy inflow was already included in the pool's magnitude). This finding partially explains the insignificant parameters estimates in the case of the stock-flow specification (where the newcomers first scan available job offers - the stock).

It seems that during the analysed time span the job seekers looked among the old and new job offers. The random matching assumes that collecting information is costly. Therefore the job creation process could be improved if the information in the market was improved. In random matching the agents are assumed to be homogenous. If there were major changes in the structure of the job seekers or job vacancies, the average matching rate could change. For example, if large emigration was not random from unemployment pool, its structure changed which could have affected the matching probability.

Augmented matching function estimates implied no changes in the efficiency of the labour market matching process. Other analyses which incorporated directly the potential determinants of the efficiency of the matching process, most often covered inhomogeneous time spans. Some of them used various forms of the time trend, but qualitative conclusions of a comparative analysis due to variously temporally and spatially aggregated data are limited.

Disaggregated analysis implied that during the 2003-2008 time span the labour market tightness indices increased, unemployment rates decreased and mismatch indices increased. A comparison of the results to the PadoaSchioppa (1991) approach criteria does not lead to unambiguous qualitative conclusions. The initial and final values of $M_{4}$ for occupational and regional dimensions actually lay within the mean confidence intervals. This suggests that the dispersion index did not change considerably in the whole period. In compiling this conclusion with Table 3 it seems more appropriate to claim that the period of 2003-2008 was characterized by lower aggregate 
disequilibrium. This finding would be in line with the matching function estimates. Changes in the labour market, including the expansion phase of the business cycle and non-negligible emigration, induced large outflows from the unemployment pool and increased job creation. This could have decreased disequilibrium between demand and supply in the labour market.

\section{CONCLUDING REMARKS}

In this article the author examined the potential changes in the efficiency of the labour market matching process along a downward sloping Beveridge curve. The analysis was based primarily on registered unemployment data for the Polish economy in 2003-2008. The movement along the $U V$ curve should have been associated with aggregate activity changes and not the reallocation ones. Estimation of aggregate matching function models, while econometrically handling for a temporal aggregation bias in the data, implied no changes in the efficiency. It was hard, however, to confirm the assumption that agents' pools were homogenous, or that they remained unchanged during the analysed period. Finally, the disaggregated analysis (in regional and occupational dimensions) was based on the mismatch concept. Various indicators showed an increase in mismatch, although the values of particular indices did not change significantly. Summarizing, the analysed time span was characterized by an increase in the labour market tightness indices, a decrease in the unemployment rates and actually minor changes in mismatch. This set of changes indicates a lower aggregate disequilibrium. Random matching and lower aggregate disequilibrium imply the need to improve information to enhance the job creation process.

\section{REFERENCES}

Abraham, K., Mismatch and Labour Mobility: Some Final Remarks, [in:] Padoa-Schioppa, F. (ed.), 1991.

Act on Promotion of Employment and Labour Market Institutions of 2004, art. 36, p. 5 (Dz. U. 2004, No. 99, 1001 with later amendments), 1991.

Antolín, P., Gross Worker Flows: How Does the Spanish Evidence Fit the Stylized Facts, "Labour" 13 (2), pp. 549-585, 1999.

Badanie ankietowe rynku pracy. Raport 2012 [Labour Market Survey. Report 2012]. Instytut Ekonomiczny National Bank of Poland, http://www.nbp.pl, access: 01.03.2013.

Blanchard, O., Diamond, P., The Beveridge Curve, "Brookings Papers on Economic Activity", pp. 1-76, 1989. 
Blanchard, O., Diamond, P., Ranking, Unemployment Duration, and Wages, "Review of Economic Studies", 61, pp. 417-434, 1994.

Central Statistical Office, http://www.stat.gov.pl, access: 20.03.2014.

Coles, M., Turnover Externality with Marketplace Trading, "International Economic Review", Vol. 40, No. 4, pp. 851-868, 1999.

Coles, M., Petrongolo, B., A Test Between Stock-Flow Matching and the Random Matching Function Approach, "International Economic Review", Vol. 49, no. 4, pp. 1113-1141, 2008.

Coles, M., Smith, E., Marketplace and Matching, "International Economic Review”, Vol. 39, No. 1 (Feb.), pp. 239-254, 1998.

Diamond, P., Aggregate Demand Management in Search Equilibrium, "The Journal of Political Economy", Vol. 90, issue 5 (Oct.), pp. 881-894, 1982.

Drozdowicz-Bieć, M., Metoda konstrukcji Barometru Ogłoszeń o Pracy [The Method of Constructing Vacancies Barometer]. Bureau for Investments and Economic Cycles LLC., Warszawa-Rzeszów, 2004.

Drozdowicz-Bieć, M., Cykle i wskaźniki koniunktury [Business Cycles and Indicators]. Wydawnictwo Poltext, Warszawa, 2012.

Eurostat, http://epp.eurostat.ec.europa.eu access: 01.09.2013.

Gałecka, E., Dopasowania podażowej i popytowej strony rynku pracy. Analiza na przykładzie Polski w latach 1998-2007 [Labour Market Matching Models. The Analysis for the Polish Labour Market in 1998-2007], dissertation, University of Łódź, unpublished manuscript, 2008.

Gałecka-Burdziak, E., Mechanisms of Labour Market Matching of Job Seekers and Vacancies, $\mathrm{PhD}$ dissertation, Warsaw School of Economics, unpublished manuscript, 2013.

Gałecka-Burdziak, E., Randomness or Stock-flow: Which Mechanism Describes Labour Market Matching in Poland?, "Baltic Journal of Economics", 17:2, pp. 119-135, 2017.

Gregg, P., Petrongolo, B., Stock-flow Matching and the Performance of the Labor Market, "European Economic Review", 49, pp. 1987-2011, 2005.

Hall, E., A Theory of the Natural Unemployment Rate and the Duration of Employment, "Journal of Monetary Economics", 5, pp. 153-169, 1979.

Jackman, R., Roper, S., Structural Unemployment, "Oxford Bulletin of Economics and Statistics", 49(1), pp. 9-37, 1987.

Lehmann, H., Active Labour Market Policies in the OECD and in Selected Transition Economies, World Bank Policy Research Working Paper No 1502, 1995.

Lindeboom, M., van Ours, J., Renes, G., Matching Employers and Workers: An Empirical Analysis of the Effectiveness of Search, Oxford Economic Papers, New Series, Vol. 46, No. 1, pp. 45-67, 1994.

Ministry of Labour and Social Policy, http://www.mpips.gov.pl, access: 01.03.2013.

Padoa-Schioppa, F. (ed.), Mismatch and Labour Mobility. Cambridge University Press, Cambridge, 1991.

Pater, R., Cykle koniunkturalne na polskim rynku pracy i ich zaktócenia [Business Cycles in the Polish Labour Market and Their Distortions], PhD dissertation, Warsaw School of Economics, unpublished manuscript, 2010. 
Petrongolo, B., Pissarides, C., Looking into the Black Box: A Survey of the Matching Function, "Journal of Economic Literature", Vol. XXXIX (June), pp. 390-431, 2001.

Petrongolo, B., Pissarides, C., Scale Effects in Markets With Search, "The Economic Journal", 116, pp. 21-44, 2006.

Pissarides, C., The Search Equilibrium Approach to Fluctuations in Employment, "American Economic Review", Vol. 78, No. 2, pp. 363-368, 1988.

Puhani, P., Public Training and Outflows from Unemployment. An Augmented Matching Function Approach on Polish Regional Data, William Davidson Institute Working Papers Series No. 258, 1999.

Registered unemployment 2003-2008, Public Employment Services http://www.psz.praca. gov.pl access: 01.09.2013.

Roszkowska, S., Aggregate Matching Function. The Case of Poland, "Central European Journal of Economic Modelling and Econometrics”, Vol. 1, issue 2, pp.157-177, 2009.

Shapiro, C., Stiglitz, J., Equilibrium Unemployment as a Worker Discipline Device, "The American Economic Review", Vol. 74, No. 3, pp. 433-444, 1984.

Taylor, C., The Long Side of the Market and the Short End of the Stick: Bargaining Power and Price Formation in Buyers', Sellers' and Balanced Markets, "The Quarterly Journal of Economics", pp. 837-855, 1995.

Received: June 2014, revised: August 2016 